\title{
SISTEM PAKAR PENDIAGNOSA PENYAKIT ANAK MENGGUNAKAN CERTAINTY FACTOR (CF)
}

\author{
Luther A. Latumakulita ${ }^{1)}$ \\ ${ }^{1)}$ Program Studi Matematika FMIPA Universitas Sam Ratulangi \\ Jl. Kampus Unsrat Manado 95115 \\ e-mail: alexalatu@gmail.com
}

\begin{abstract}
ABSTRAK
Telah dibangun sistem pakar untuk mendiagnosa penyakit anak dengan penanganan faktor ketidakpastian menggunakan certainty factor (CF). Tahapan pembangunan sistem ini dimulai dengan mengakuisisi pengetahuan dari dokter ahli anak kemudian membangun basis pengetahuan dan memberikan nilai CF pada setiap gejala yang terkait dengan suatu penyakit anak dalam range nilai 0 dan1. Dengan memilih gejala-gejala penyakit yang dilihat atau dirasakan maka sistem dapat mendiagnosa penyakit anak dengan menampilkan tiga penyakit dengan nilai $\mathrm{CF}$ terbesar yang diurutkan secara descending.
\end{abstract}

Kata kunci : Certainty faktor, sistem pakar, penyakit anak

\section{EXPERT SYSTEM FOR DIAGNOSING CHILD DISEASE BY USING CERTAINTY FACTOR (CF)}

\begin{abstract}
An expert system has been conducted for diagnosing child disease by using certainty factor (CF) with uncertainty variable. This conducting phase was started by acquiring the pediatrician's knowledge which was then followed by conducting knowledge base and giving CF value on every symptom which bonds to a child disease on 0 to 1 range. By choosing the syptoms of the disease that have been observed or felt, the system would be able to diagnose the child disease by showing the three diseases which have been listed descendingly from the biggest $\mathrm{CF}$ value.
\end{abstract}

Keywords: certainty factor, expert system, child disease

\section{PENDAHULUAN}

\section{Latar Brlakang}

Ketersediaan dokter ahli dan tenaga medis relatif masih kurang khususnya di daerah-daerah pelosok dan terpencil. Hal ini membuat masyarakat mengalami kesulitan dalam mendiagnosa penyakit tertentu sehingga penanganan medis menjadi terlambat dan dapat mengakibatkan resiko kematian.

Anak sangat rentan terhadap kuman penyakit sehingga sebagai orang tua perlu untuk secara cepat memperoleh informasi tentang tingkat keparahan penyakit anak walaupun tidak tersedia dokter ahli anak sehingga orang tua mempunyai pengetahuan yang cukup untuk melakukan tindakan awal.

Keterbatasan ketersediaan tenaga paramedis khususnya dokter ahli anak di daerah terpencil dapat diatasi dengan mengadopsi kepakaran dokter ahli anak kedalam suatu sistem berbasis komputer yang mampu melakukan diagnosa layaknya seorang dokter ahli anak. Untuk menangani factor ketidakpastian dalam mendiagona penyakit anak maka sistem pakar tersebut dirancang dengan menggunakan teori-teori ketidak pastian seperti yang akan di bahas pada bab selanjutnya. Sistem pakar yang akan dibangun dalam penelitian ini menggunakan Certainty Factor. (CF) untuk penanganan masalah ketidakpastian.

\section{Perumusan Masalah}

Dalam penelitian ini yang menjadi permasalahan utama adalah bagaimana membangun suatu sistem berbasis komputer yang dapat mengadopsi kepakaran dokter ahli anak dengan menggunakan Certainty Factor. 
(CF) dalam menangani masalah ketidakpastian. sehingga masyarakat dapat menngunakan sistem tersebut untuk melakukan diagnosa terhadap penyakit anak.

\section{TINJAUAN PUSTAKA}

\section{Sistem Pakar}

Sistem pakar adalah suatu program komputer yang dirancang untuk mengambil keputusan seperti keputusan yang diambil oleh seorang atau beberapa orang pakar. Dalam penyusunannya, sistem pakar mengkombinasikan kaidah-kaidah penarikan kesimpulan (inference rules) dengan basis pengetahuan tertentu yang diberikan oleh satu atau lebih pakar dalam bidang tertentu. Kombinasi dari kedua hal tersebut disimpan dalam komputer, yang selanjutnya digunakan dalam proses pengambilan keputusan untuk penyelesaian masalah tertentu. Tujuan utama sistem pakar bukan untuk menggantikan kedudukan seorang ahli atau seorang pakar, tetapi hanya untuk memasyarakatkan pengetahuan dan pengalaman dari para pakar. Seiring pertumbuhan populasi manusia, maka di masa yang akan datang sistem pakar ini diharapkan sangat berguna membantu dalam hal pengambilan keputusan (Giarratano dan Riley, 2005).

Berikut ini ada beberapa definisi tentang sistem pakar menurut para ahli, antara lain :

a) Sistem pakar adalah sistem berbasis komputer yang menggunakan pengetahuan, fakta, dan teknik penalaran dalam memecahkan masalah, yang biasanya hanya dapat diselesaikan oleh seorang pakar dalam bidang tertentu (Martin dan Oxman, 1988).

b) Sistem pakar merupakan bidang yang dicirikan oleh sistem berbasis pengetahuan (Knowledge Base System), memungkinkan komputer dapat berfikir dan mengambil keputusan dari sekumpulan kaidah (Ignizio, 1991).

c) Sistem pakar adalah program komputer yang didesain untuk meniru kemampuan memecahkan masalah dari seorang pakar. Pakar adalah orang yang memiliki kemampuan atau mengerti dalam menghadapi suatu masalah. Lewat pengalaman, seorang pakar mengembangkan kemampuan yang membuatnya dapat memecahkan permasalahan dengan hasil yang baik dan efisien (John Durkin, 1994)

d) Sistem pakar adalah salah satu cabang kecerdasan buatan yang menggunakan pengetahuan-pengetahuan khusus yang dimiliki oleh seorang ahli untuk menyelesaikan suatu masalah tertentu (Giarratano dan Riley, 2005).

\section{Certainty Factor}

Sistem pakar harus mampu bekerja dalam ketidakpastian (Giarratano dan Riley, 2005). Sejumlah teori telah ditemukan untuk menyelesaikan ketidakpastian, antara lain:
a) Probabilitas klasik (classical probability)
b) Probabilitas Bayes (Bayesian probability)
c) Teori Hartley berdasarkan himpunan klasik (Hartley theory based on classical sets)
d) Teori Shannon berdasarkan pada probabilitas (Shanon theory based on probability)
e) Teori Dempster-Shafer (Dempster- Shafer theory)
f) Teori fuzzy Zadeh (Zadeh's fuzzy theory)
g) Faktor kepastian (certainty factor) Rumus umum menentukan Certainty Factor :

$$
\mathrm{CF}[\mathrm{H}, \mathrm{E}]=\mathrm{MB}[\mathrm{H}, \mathrm{E}]-\mathrm{MD}[\mathrm{H}, \mathrm{E}] \quad \ldots . .(1)
$$$$
\text { dengan : }
$$$$
\mathbf{C F}[\mathbf{h}, \mathbf{e}]=\text { faktor kepastian }
$$$$
\mathbf{M B}[\mathbf{h}, \mathbf{e}]=\text { ukuran kepercayaan terhadap }
$$$$
\text { hipotesis } \mathrm{h} \text {, jika diberikan }
$$$$
\text { evidence e (antara } 0 \text { dan 1) }
$$

$\mathbf{M D}[\mathbf{h}, \mathbf{e}]=$ ukuran ketidakpercayaan terhadap evidence h, jika diberikan evidence e (antara 0 da 1 )

Suatu sistem pakar seringkali memiliki kaidah lebih dari satu dan terdiri dari beberapa premis yang dihubungkan dengan $A N D$ atau $O R$. Pengetahuan mengenai premis dapat juga tidak pasti, hal ini dikarenakan besarnya nilai (value) CF yang diberikan oleh pasien saat menjawab pertanyaan sistem atas premis (gejala) yang dialami pasien atau dapat juga dari nilai $\mathrm{CF}$ hipotesa.

Formula CF untuk beberapa kaidah yang mengarah pada hipotesa yang sama menurut Kusrini (2006), dapat dituliskan sebagai berikut : 


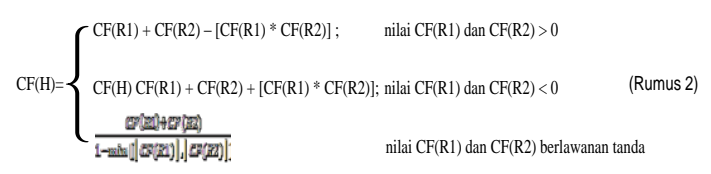

\section{METODE PENELITIAN}

dalam penelitian ini:

a) Studi Pustaka

Studi pustaka mempelajari defenisi

b) Wawancara dengan dokter ahli anak untuk mendapatkan data penyakit anak dan gejala-gejalanya serta teknik inferensi untuk memperoleh kesimpulan

c) Metode Pengembangan Sistem

Dalam pengembangan sistem beberapa tahapan yang dilakukan adalah:

- Tahapan Akuisisi Pengetahuan

Pada bagian ini dilakukan proses mengubah data-data menjadi perumusan pengetahuan awal tentang penyakit anak. Pada bagian ini melibatkan pakar penyakit mata sebagai nara sumber.

- Tahapan Perancangan Sistem

Pada bagian ini, rumusan pengetahuan yang telah diperoleh diolah lebih lanjut menjadi bentuk pengetahuan dalam format JIKA <anteseden> MAKA <konsekuen>. Konsekuen merupakan kesimpulan berdasarkan rule dari basis pengetahuan. Dalam tahapan ini juga dirancang interface menyangkut interface untuk penginputan data dan interface untuk proses diagnose

- Tahapan Implementasi

Dalam tahapan ini rancangan yang sudah dibuat pada tahapan sebelumnya di terjemahkan dalam sintaks bahasa pemograman

- Tahapan Pengujian Sistem

Dalam tahapan ini data diinput dan proses diagnose dilakukan keudian output sistem berupa hasil diagnose dianalisis untuk menguji kebenarannya sesuai dengan teori-teori yang dilibatkan.

\section{Akuisisi Pengetahuan}

Berdasarkan pengetahuan yang diperoleh dari pakar maka sibangun table keputusan sebagai dasar pembuatan mesin inferensi. Tabel keputusan Sistem
Pendiagnosa Penyakit Anak Menggunakan Certainty Factor dapat dilihat pada tabel 1.

Nilai Certainty Factor ditentukan untuk setiap gejala yang melekat pada suatu penyakit dan dalam sistem ini nilai certainty factor dapat diupdate.

Dari Tabel keputusan diatas maka dapat dibentuk tujuh aturan (rule) Sebagai berikut

R1: IF demam AND lesu AND malas makan AND muntah berak AND pendarahan pada kulit AND mimisan AND sakit kepala THEN penyakit=DBD

R2: IF demam AND sakit kepala AND tubuh menggigil AND denyut jantung lemah AND badan lemah AND Nyeri otot myalgia AND Tidak nafsu makan AND konstipasi THEN penyakit=Demam Tifoit

R3: IF demam AND nyeri tenggorokan AND hidung meler AND batuk AND bercak koplik AND nyeri otot AND mata merah THEN penyakit=Campak

R4: IF buang air besar terus menerus AND mual AND muntah-muntah AND pegal pada punggung AND perut sering berbunyi THEN penyakit=Diare

R5: IF buang air besar terus menerus AND mual AND muntah-muntah AND pegal pada punggung AND perut sering berbunyi THEN penyakit=Tetanus

R6: IF demam AND lesu AND sakit kepala AND tubuh menggigil AND tidak nafsu makan AND sakit otot AND nyeri perut AND nyeri punggung THEN penyakit=Malaria

R7: IF demam AND lesu AND sakit kepala AND mual AND nyeri punggung AND tonjolan-tonjolan kemerahan AND THEN penyakit=Varisela 
Tabel 1. Tabel Keputusan Penyakit Berdasarkan Gejala

\begin{tabular}{|c|c|c|c|c|c|c|c|}
\hline \multicolumn{8}{|c|}{ Tabel Keputusan Penyakit Berdasarkan Gejalanya } \\
\hline \multirow[b]{2}{*}{ Gejala } & \multicolumn{7}{|c|}{ Penyakit } \\
\hline & P01 & P02 & P03 & P04 & P05 & P06 & P07 \\
\hline Demam & $\sqrt{ }$ & 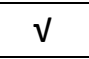 & v & & & $\checkmark$ & v \\
\hline Lesu & $\sqrt{ }$ & & & & & $\checkmark$ & \\
\hline Malas makan & $\sqrt{ }$ & & & & & & \\
\hline Muntah berak & $\sqrt{ }$ & & & & & & \\
\hline Pendarahan pada kulit & $\sqrt{ }$ & & & & & & \\
\hline Mimisan & $\sqrt{ }$ & & & & & & \\
\hline Sakit Kepala & $\sqrt{ }$ & v & & & $\mathrm{v}$ & $\mathrm{v}$ & $\mathrm{v}$ \\
\hline Tubuh menggigil & & 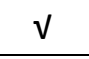 & & & $\sqrt{ }$ & $v$ & \\
\hline Denyut jantung lemah & & v & & & & & \\
\hline Badan lemah & & $\sqrt{ }$ & & & & & \\
\hline Nyeri otot myalgia & & $\mathrm{v}$ & & & & & \\
\hline Tidak nafsu makan & & $\sqrt{ }$ & & & & $\checkmark$ & \\
\hline Konstipasi & & $\sqrt{ }$ & & & & & \\
\hline Sakit perut & & $\mathrm{v}$ & & & & & \\
\hline Penyebaran vlek merah muda & & $\mathrm{v}$ & & & & & \\
\hline Nyeri tenggorokan & & & v & & $\sqrt{ }$ & & \\
\hline Hidung meler & & & $\mathrm{v}$ & & & & \\
\hline Batuk & & & $\mathrm{V}$ & & & & \\
\hline Bercak Koplik & & & $\mathrm{V}$ & & & & \\
\hline Nyeri otot & & & $\mathrm{V}$ & & & & \\
\hline Mata merah & & & $\mathrm{V}$ & & & & \\
\hline Buang air besar terus menerus & & & & $\sqrt{ }$ & & & \\
\hline Mual & & & & $\sqrt{ }$ & & & $\checkmark$ \\
\hline Muntah-muntah & & & & $\sqrt{ }$ & & & \\
\hline Pegal pada punggung & & & & $\mathrm{V}$ & & & \\
\hline Perut sering berbunyi & & & & $\checkmark$ & & & \\
\hline Kekakuan rahang & & & & & $\sqrt{ }$ & & \\
\hline Nyeri telan & & & & & $\sqrt{ }$ & & \\
\hline Kejang otot & & & & & $\sqrt{ }$ & & \\
\hline Sakit Otot & & & & & & $\sqrt{ }$ & \\
\hline Nyeri perut & & & & & & $\sqrt{ }$ & \\
\hline Nyeri punggung & & & & & & $\mathrm{V}$ & $\mathrm{V}$ \\
\hline Tonjolan-tonjolan kemerahan & & & & & & & $\sqrt{ }$ \\
\hline
\end{tabular}

Keterangan Penyakit: P01: DBD (Demam Berdarah Dengue), P02: Demam Tifoid, P03: Campak, P04: Diare, P05: Tetanus, P06: Malaria, P07: Varisela (Cacar Air) 


\section{Perancangan Basis Data}

Sistem manajemen database yang digunakan adalam Microsoft Access 2003 dengan struktur tabel sebagai berikut:

1. Tabel User.

Tabel user digunakan untuk menyimpan data user sebagai admin, debgab struktur dapat dilihat pada tabel 2 .

Tabel 2. Struktur Tabel User

\begin{tabular}{|c|l|c|c|l|}
\hline No. & \multicolumn{1}{|c|}{ Field } & Tipe & Lebar & \multicolumn{1}{|c|}{ Keterangan } \\
\hline 1 & Nama User & Text & 20 & User Admin \\
\hline 2 & Passwor & Text & 20 & Password Admin \\
\hline
\end{tabular}

2. Tabel Penyakit.

Tabel penyakit digunakan untuk menyimpan data penyakit, dengan struktur pada Tabel 3 .

Tabel 3. Struktur Tabel Penyakit

\begin{tabular}{|c|l|c|c|l|}
\hline No. & \multicolumn{1}{|c|}{ Field } & Tipe & Lebar & \multicolumn{1}{|c|}{ Keterangan } \\
\hline 1 & $\begin{array}{l}\text { Kode } \\
\text { Penyakit }\end{array}$ & Text & 7 & Primary key, Kode Penyakit \\
\hline 2 & $\begin{array}{l}\text { Nama } \\
\text { Penyakit }\end{array}$ & Text & 100 & Nama Penyakit \\
\hline 3 & Penyebab & Memo & - & Penyebab penyakit \\
\hline
\end{tabular}

\section{Tabel Gejala}

Tabel gejala digunakan untuk menyimpan semua gejala penyakit yang terkait dengan penyakit anak (Tabel 4).

Tabel 4. Struktur Tabel Gejala

\begin{tabular}{|c|c|c|c|c|}
\hline No. & Field & Tipe & Lebar & Keterangan \\
\hline 1 & Kode Gejala & Text & 7 & Primary key, kode gejala penyakit \\
\hline 2 & Nama Gejala & Text & 150 & Nama Gejala Penyakit \\
\hline 3 & $\begin{array}{l}\text { Keterangan } \\
\text { Gejala }\end{array}$ & Memo & - & Keterangan \\
\hline
\end{tabular}

\section{Tabel Penyakit_Gejala.}

Tabel Penyakit_Gejala adalah tabel yang digunakan untuk aturan (rule) yang telah didefenisikan sebelumnya (Tabel 5).

Tabel 5. Struktur Tabel Penyakit_Gejala

\begin{tabular}{|c|l|c|c|l|}
\hline No. & \multicolumn{1}{|c|}{ Field } & Tipe & Lebar & \multicolumn{1}{|c|}{ Keterangan } \\
\hline 1 & $\begin{array}{l}\text { Kode } \\
\text { Penyakit }\end{array}$ & Text & 7 & Kode Penyakit \\
\hline 2 & Kode Gejala & Text & 7 & Kode Gejala Penyakit \\
\hline 3 & CF & Number & - & Nilai CF Gejala Terhadap Penyakit \\
\hline
\end{tabular}

\section{HASIL DAN PEMBAHASAN}

Bahasa pemograman yang digunakan dalam membangun sistem ini adalah Visual Basic 6.0. Menu utama dari sistem dapat dilihat pada gambar 1 .

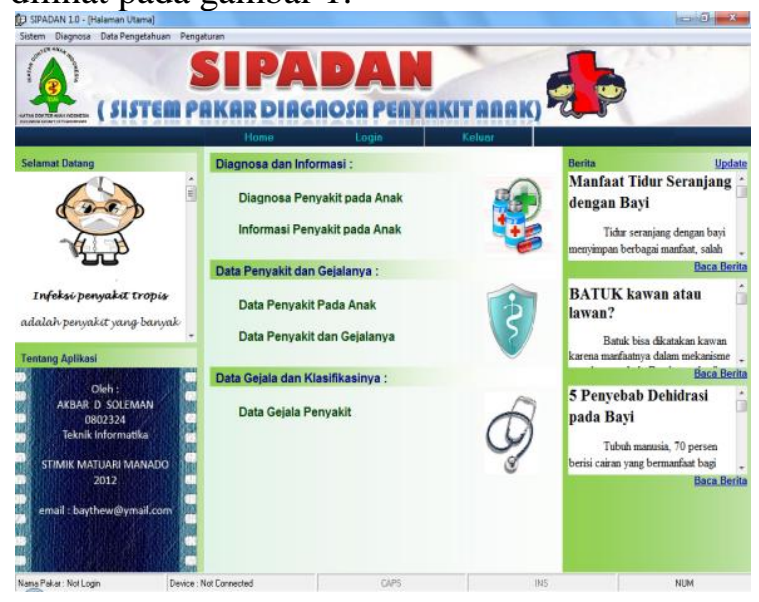

Gambar 1. Tampilan Menu Utama

Untuk dapat melakukan pengolahan database pengetahuan berupa data penyakit, gejala dan rule maka user harus terlebih melakukan proses login untk memastikan user tersebut sebagai admin. Tampilan dari layar menu login dapat dilihat pada gambar 2.

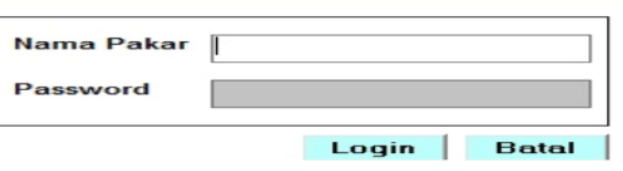

Gambar 2. Tampilan Menu Login

User sebagai admin yang telah melakukan proses login dapat mengolah data penyakit melalui form penyakit seperti gambar 3 berikut ini:

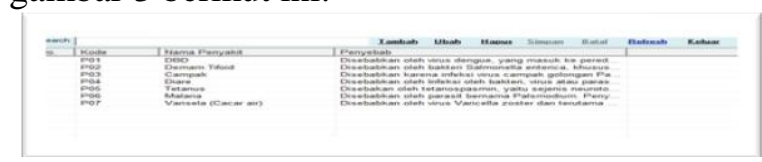

Gambar 3. Tampilan Form Penyakit

Pengolahan data gejala penyakit dapat dilakukan melalui Form Gejala Penyakit seperti terlihat pada gambar 4 . 


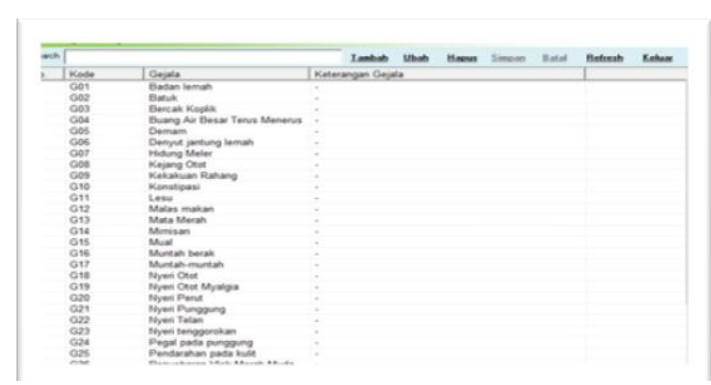

Gambar 4 Tampilan Form Gejala Penyakit

Setelah data gejala dan data penyakit diinput maka langkah selanjutna adalah membangun basis pengetahuan dengan cara melakukan penginputan data aturan (rules) melalui form Rule seperti pada gambar 5.

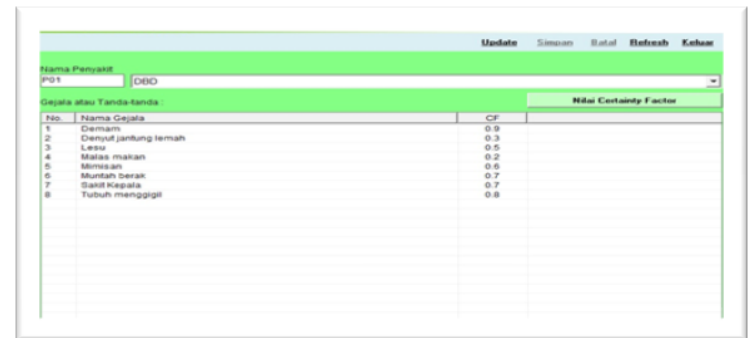

Gambar 5. Tampilan Form Rule

Nilai Certainty Factor

(CF) ditentukan untuk setiap gejala yang berkorespondensi dengan penyakit tertentu dalam range nilai $0 . .1$. Nilai ini mewakili keyakinan seorang pakar dalam hal ini dokter anak terhadap suatu gejala yang mempengaruhi terjadinya suatu penyakit tertentu.

Selanjutnya proses diagnosis dapat dilakukan melalui form diagnosa seperti yang terlihat pada gambar 6 .

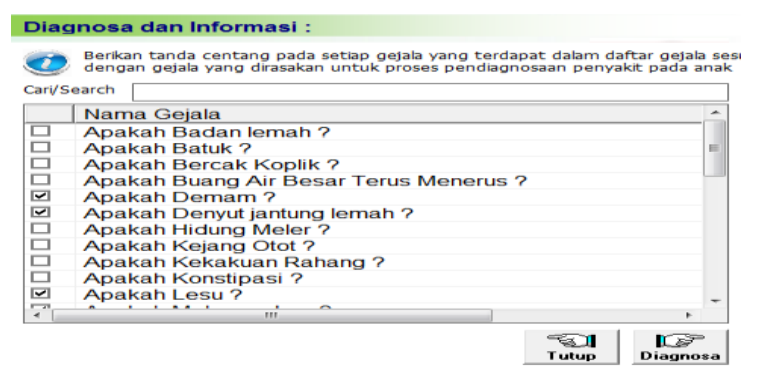

Gambar 6. Tampilan Form Diagnosa

Form diagnosa dapat diakses tanpa melalui proses login. Semua data gejala penyakit yang telah tersimpan dalam tabel gejala ditampilkan dan user dapat memilih gejala yang dirasakan atau dilihat pada anak dengan cara mencentang button chek yang tersedia. Berdasarkan gejala-gejala yang dipilih tersebut maka sistem akan menjalankan mesin inferensi yang telah dibuat menurut pendefenisian aturan (rule) yang telah dilakukan sebelumnya. Untuk menghitung tingkat kepercayaan terjadinya penyakit yang terdiagnosa menggunakan nilai CF dan hasilnya dapat dilihat seperti pada gambar 7 berikut ini:

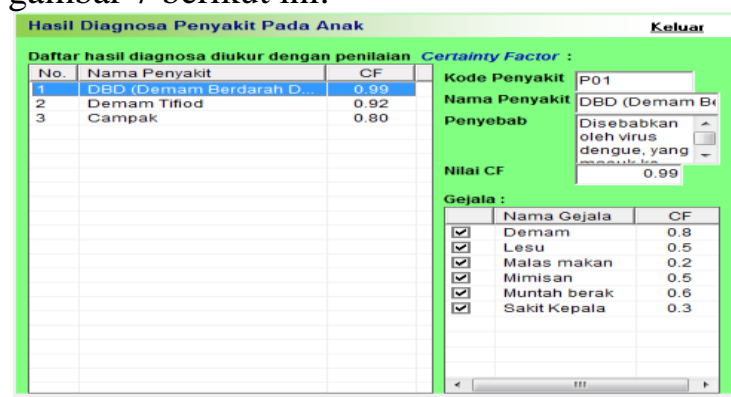

Gambar 7 Tampilan Form Hasil Diagnosa

Dengan Menggunakan (Rumus 2) nilai CF untuk setiap penyakit dihitung kemudian ditampilkan tiga jenis penyakit dengan nilai $\mathrm{CF}$ terbesar yang diurutkan secara descending. Berdasarkan gejala dipilih dan nilai CF gejala pada Penyakit DBD seperti pada tabel 6 berikut:

Tabel 6. Nilai CF Gejala Pada Penyakit DBD

\begin{tabular}{|c|l|c|c|}
\hline No. & \multicolumn{1}{|c|}{ Gejala } & Penyakit & CF \\
\hline 1 & Demam & DBD & 0,8 \\
\hline 2 & Lesu & DBD & 0,5 \\
\hline 3 & Malas Makan & DBD & 0,2 \\
\hline 4 & Mimisan & DBD & 0,5 \\
\hline 5 & Muntah Berak & DBD & 0,6 \\
\hline 6 & Sakit Kepala & DBD & 0,3 \\
\hline
\end{tabular}

maka nilai CF Penyakit Denam Berdarah Dengue (DBD) deperoleh dengan cara: $\mathrm{CF}(\mathrm{A})=\mathrm{CF}(1)+[\mathrm{CF}(2) *(1-\mathrm{CF}(1)]=0,8$ $+[0,5 *(1-0,8)]=0,9$

$\mathrm{CF}(\mathrm{B})=\mathrm{CF}(3)+[\mathrm{CF}(\mathrm{A}) *(1-\mathrm{CF}(3)]=0,2$ $+[0,9 *(1-0,2)]=0,92$

$\mathrm{CF}(\mathrm{C})=\mathrm{CF}(4)+[\mathrm{CF}(\mathrm{B}) *(1-\mathrm{CF}(4)]=0,5$ $+[0,92 *(1-0,5)]=0,96$

$\mathrm{CF}(\mathrm{D})=\mathrm{CF}(5)+[\mathrm{CF}(\mathrm{C}) *(1-\mathrm{CF}(5)]=0,6$ $+[0,96 *(1-0,6)]=0,984$

$\mathrm{CF}(\mathrm{E})=\mathrm{CF}(6)+[\mathrm{CF}(\mathrm{D}) *(1-\mathrm{CF}(6)]=0,3$ $+[0,984 *(1-0,3)]=0,9888$

Sehingga CF penyakit DBD (Demam Berdarah Dengue) adalah 0,9888 (dibulatkan menjadi 0,99atau 99\%), dan Berdasarkan 
nilai CF gejala pada penyakit Demam Tifoid seperti yang terlihat pada tabel 7 .

Tabel 7. Nilai CF Gejala Pada Penyakit Demam Tifoid

\begin{tabular}{|c|l|c|c|}
\hline No. & \multicolumn{1}{|c|}{ Gejala } & Penyakit & CF \\
\hline 1 & Demam & Demam Tifoid & 0,83 \\
\hline 6 & Sakit Kepala & Demam Tifoid & 0,50 \\
\hline
\end{tabular}

Maka nilai CF Penyakit Demam Tifoid adalah :

$\mathrm{CF}(\mathrm{A})=\mathrm{CF}(1)+[\mathrm{CF}(2) *(1-\mathrm{CF}(1)]=$ $0,83+[0,50 *(1-0,83)]=0,92$

Dan untuk penyakit campak yang hanya memiliki satu gejala dari gejala yang dipilih yaitu gejala demam $(\mathrm{CF}=80)$ maka $\mathrm{CF}$ Penyakit campak adalah:

$\mathrm{CF}(\mathrm{A})=\mathrm{CF}(1)+[\mathrm{CF}(2) *(1-\mathrm{CF}(1)]=$ $0,80+[0,0 *(1-0,83)]=0,80$

Dengan cara yang sama maka semua penyakit dihitung nilai CF. Nilai CF Dari hasil perhitungan nilai $\mathrm{CF}$ untuk semua penyakit diperoleh Penyakit Demam Berdarah Dengue mempunyai nilai $\mathrm{CF}$ terbesar yaitu 0,99 Maka penyakit DBD yang di fired sebagai kesimpulan hasil diagnosis menurut gejala yang dipilih.

\section{KESIMPULAN}

Sistem Pakar Pendiagnosa Penyakit Anak Menggunakan Certainty Factor dapat digunakan untuk mendiagnosa penyakit anak dengan tingkat kepercayaan yang telah ditentukan oleh pakar terhadap gejala-gejala yang mempengaruhi probabilitas terjadinya suatu penyakit anak. Sistem ini akan optimal jika seorang atau sekelompok pakar dalam hal ini dokter ahli anak telah mendefenisikan secara jelas nilai CF setiap gejala penyakit terhadap kemungkinan terjadinya penyakit anak.

\section{DAFTAR PUSTAKA}

Durkin, J. 1994. Expert System: Design and Development. Prentice-Hall Int. Inc., New Jersey.

Giarratano, J. \& Riley, G. 2005. Expert Sistem: Principles and Programming, 4th Edition. PWS Publishing Company, Boston.

Ignizio, J. P. 1991. Introduction To Expert Systems : The Development and Implementation of Rule-Based Expert Systems. McGraw-Hill,Inc., New York.

Kusrini. 2006. Sistem Pakar Teori dan Aplikasi. Penerbit Andi, Yokyakarta.

Martin, J \& Oxman, S. 1988. Building Expert System a tutorial. Prentice Hall, New Jersey. 